\title{
DESIGN OF COMPACT PLANAR RAT-RACE AND BRANCH- LINE HYBRID COUPLERS USING POLAR CURVES
}

\section{Johan Joubert and Johann W. Odendaal}

Centre for Electromagnetism, Department of Electrical, Electronic and Computer Engineering, University of Pretoria, Pretoria 0002, South Africa; Corresponding author: jjoubert@up.ac.za

\begin{abstract}
An approach where polar curves are used to miniaturize hybrid couplers is presented. The design of such couplers can be done with the optimization of a few parameters using full-wave analysis software. The results show similar or better electrical performance for a rat-race and branch-line coupler with respectively a 75\% and 50\% size reduction.
\end{abstract}

Key words: hybrid coupler; rat-race coupler; branch-line coupler; polar curve; compact coupler 


\section{INTRODUCTION}

The design of compact rat-race and branch-line hybrid couplers for wireless communication systems is a very relevant topic because of the numerous practical applications where smaller device size is an important design requirement [1-8]. Using lumped elements at strategic points, or only lumped elements, can result in significant size reduction, but are more suited to monolithic-microwave integrated circuit (MMIC) realization [1]. For realization using standard single-layer printed-circuit-board manufacturing one of the options for achieving size reduction is the use of shorter, loaded transmission line sections that are equivalent to quarter-wavelength transmission line sections [1-5]. A second option is to meander the transmission line sections in such a way that the overall surface area of the device is reduced [6-8]. The smallest of these designs achieved reductions in area size of up to 92\% [4] for a rat-race coupler, and up to $72 \%$ [5] for a branch-line coupler, but at the cost of significantly worse electrical performance in terms of bandwidth. In fact, it is only the design by Eccleston and Ong [1], with reductions of $68 \%$ and $51 \%$ for rat-race and branch-line couplers respectively, that specifically reported that their designs have frequency responses and bandwidths similar to conventional size couplers.

In this paper results of a new miniaturization approach, using simple polar curves to meander the transmission line sections of the couplers, are presented. The results presented will show that the technique may be used to reduce the surface area of a rat-race hybrid and a branch-line hybrid coupler by at least $75 \%$ and $50 \%$ respectively, with similar or better electrical performance when compared to conventional size couplers.

\section{BASIC GEOMETRY AND DESIGN}

In this paper the size reduction of the rat-race and branch-line couplers is simply based on the substitution of the microstripline ring of a conventional circular form of the coupler with a 
microstripline "modified ring" in the form of a polar curve. The oscillating path of the polar curve should have the same electrical length as the circular path of the conventional circular form of the coupler, and the characteristic impedances of the two microstriplines should ideally be the same. A simple polar curve can be described by the following equation:

$$
r=a+b \cos (n \theta)
$$

with $r$ the varying radial distance from the origin as function of angle $\theta$, and $a$ and $b$ two constants. The integer parameter $\mathrm{n}$ determines the number of sinusoidal variations of the polar curve through one full rotation of $\theta$. Figure 1 shows such a polar curve, as well as a short straight-line profile normal to the polar curve which can be swept along the polar generating curve to achieve a microstripline of a specific width.

This method of construction, using an analytical function for the generating curve, and an option to sweep a profile along its length to give it a specific finite width, is standard in most modern full-wave electromagnetic simulators like CST Microwave Studio [9].

\subsection{Rat-race coupler}

As reference a conventional rat-race hybrid coupler [10] was designed to operate at a center frequency of $1.8 \mathrm{GHz}$. The microstripline layout of the coupler is shown in Figure 2, with $w$ the width of the $50 \Omega$ feedlines, and $w_{1}$ and $r$ the width and radius of the $70.7 \Omega$ microstripline ring with an overall electrical length of $6 / 4 \lambda$. An approximate design was optimized in CST Microwave Studio [9] to determine accurate values for $w, w_{1}$ and $r$. The polar curve $r=a+b \cos (n \theta)$ was then used to design a quarter-size rat-race coupler (see Figure 3) using CST Microwave Studio [9]; $n$ was chosen as 12, and through optimization accurate values for $w_{1}, a$, and $b$ were determined. Because the size of the compact coupler 
was decided in advance (this can be regarded as a distinct advantage of the design method proposed in this paper), the following relationship between the design parameters of the conventional and compact rat-race couplers was enforced:

$\left[\frac{\left(r+\frac{w_{1}}{2}\right)}{\sqrt{4}}\right]_{\text {conv }}=\left(a+b+\frac{w_{1}}{2}\right)_{\text {compact }}$.

\subsection{Branch-line coupler}

A conventional branch-line hybrid coupler [10], but with a circular geometry, was also designed to operate at a center frequency of $1.8 \mathrm{GHz}$. The microstripline layout of the coupler is shown in Figure 4, with $w$ the width of the $50 \Omega$ feedlines, and $w_{1}$ and $w_{2}$ the widths of the $50 \Omega$ and $35.4 \Omega$ quarter-wavelength microstripline sections respectively, and $r$ the radius of the ring with an overall electrical length of $1 \lambda$. An approximate design was optimized in CST Microwave Studio to determine accurate values for $w, w_{1}, w_{2}$ and $r$. Sections of the polar curves $r=a_{1}+b_{1} \cos (n \theta)$ and $r=a_{2}+b_{2} \cos (n \theta)$ were then used to design a half-size

polar branch-line coupler (see Figure 5) using CST Microwave Studio [9]; $n$ was again chosen as 12 , and through optimization accurate values for $w_{1}, w_{2}, a_{1}, a_{2}, b_{1}$ and $b_{2}$ were determined. The following relationships were enforced:

$$
\left[\frac{\left(r+\frac{w_{2}}{2}\right)}{\sqrt{2}}\right]_{\text {conv }}=\left(a_{2}+b_{2}+\frac{w_{2}}{2}\right)_{\text {compact }},
$$

and

$$
a_{1}+b_{1}=a_{2}+b_{2} \text {. }
$$




\subsection{Geometry variations}

For the rat-race and branch-line coupler examples discussed in this paper $n$ was chosen as 12 . Other possible values for $n$ would be 6 or 18 (to keep the ports in the same location). The choice of the value of $n$ will have an effect on the degree of miniaturization that can be achieved - also of course depending on the substrate properties which has a direct influence on the microstripline track widths. For the rat-race coupler one can also create a configuration where you can have two microstripline feedlines (eg. for ports 1 and 4) going to the inside of the structure (for coaxial-to-microstripline transitions via the groundplane), with the other two microstripline feedlines (for ports 1 and 3) going to the outside $-n=9$ or $n=15$ will allow for such a configuration. This will create the possibility to cascade two ring-hybrid couplers (eg. a compact one within a conventional size one) on a single substrate without the use of crossovers as was done in [11]. A similar configuration can be achieved for a branchline coupler, but then different $n$ values will have to be used for different branch-line sections. This may for instance be useful when designing compact sequential feed networks for circularly polarized antennas.

\section{RESULTS}

All four of the couplers discussed in the previous section were manufactured on a Rogers RO4003 substrate with $\varepsilon_{\mathrm{r}}=3.38$, tan $\delta=0.0021$ and a thickness of $0.813 \mathrm{~mm}$, and the magnitudes and phases of the s-parameters were measured using a vector network analyzer.

The measured s-parameter results for the conventional full-size rat-race coupler are shown in Figure 6. Port 1, also referred to as the sum port [10] was used as the input port. The difference in measured magnitude and phase between $s_{21}$ and $s_{31}$ are shown in Figure 7. The same sets of measured data for the quarter-size rat-race coupler are shown in Figure 8 and Figure 9. A comparison between the two rat-race couplers in terms of bandwidth 
performance, defined in terms of reflection coefficient $(<-10 \mathrm{~dB})$, magnitude difference (within $\pm 0.5 \mathrm{~dB}$ ) and phase difference (within $\pm 5^{\circ}$ ) is given in Table 1 . The final optimized dimensions of the couplers are also presented in the table.

The measured s-parameter results for the conventional full-size branch-line coupler are shown in Figure 10. Port 1 was used as the input port. The difference in measured magnitude and phase between the coupled ports, $s_{21}$ and $s_{31}$, are shown in Figure 11. The same sets of measured data for the half-size branch-line coupler are shown in Figure 12 and Figure 13. The final design parameters and a comparison between the two branch-line couplers in terms of bandwidth performance, defined in terms of reflection coefficient $(<-10 \mathrm{~dB})$, magnitude difference (within $\pm 0.5 \mathrm{~dB}$ ) and phase difference (within $\pm 1^{\circ}$ ) is given in Table 2 .

The difference in the simulated insertion loss $\left(\right.$ at $\left.f_{0}\right)$ between the conventional and compact couplers was found to be $0.043 \mathrm{~dB}$ and $0.013 \mathrm{~dB}$ for the rat-race and branch-line couplers respectively. The slightly higher insertion loss of the compact couplers is primarily due to the reduced line widths that were determined for optimized performance of the highly curved polar profiles.

\section{CONCLUSIONS}

This paper introduced a new approach to realize compact rat-race and branch-line hybrid couplers. The geometry of these couplers is easy to enter into full-wave electromagnetic analysis software, and the design of such couplers with a pre-determined size reduction is easy to perform with a simple optimization using the full-wave analysis software. The measured results show similar or better impedance bandwidth, magnitude tracking bandwidth and phase tracking bandwidth - for a rat-race coupler with a $75 \%$ reduction in surface area, and a branch-line coupler with a 50\% reduction in surface area - as compared to conventional circular configuration rat-race and branch-line couplers. 


\section{REFERENCES}

1. K. W. Eccleston and S. H. M. Ong, Compact planar microstripline branch-line and rat-race couplers, IEEE Trans Microwave Theory Tech 51 (2003), 2119-2125.

2. S.-S. Liao, P.-T. Sun, N.-C. Chin and J.-T. Peng, A novel compact-size branch-line coupler, IEEE Microwave Wireless Compon Lett 15 (2005), 588-590.

3. D. Nesic, Slow-wave EBG microstrip rat-race hybrid ring, Electronic Lett 41 (2005), $1181-1183$

4. J. Wang, B.-Z. Wang, Y.-X. Guo, L. C. Ong and S. Xiao, Compact slow-wave microstrip rat-race ring coupler, Electronic Lett 43 (2007), 111-113.

5. J. P. Wang, B. Z. Wang, Y. X. Guo, L. C. Ong, and S. Q. Xiao, A compact slowwave microstrip branch-line coupler with high performance, IEEE Microwave Wireless Compon Lett 17 (2007), 501-503.

6. R. G. Settaluri, G. Sundberg, A. Weisshaar and V. K. Tripathi, Compact folded line rat-race hybrid couplers, IEEE Microwave Guided Wave Lett 10 (2000), 61-63.

7. H. Ghali and T. A. Moselly, Miniaturized fractal rat-race, branch-line, and coupledline hybrids, IEEE Trans Microwave Theory Tech 52 (2004), 2513-2520.

8. M. H. Awida, A. M. E. Safwat and H. El-Hennawy, Compact rat-race hybrid coupler using meander space-filling curves, Microwave Opt Technol Lett 48 (2006), 606609.

9. CST Studio Suite 2014: CST AG, Darmstadt, Germany.

10. D. M. Pozar, Microwave Engineering. $2^{\text {nd }}$ ed., John Wiley \& Sons, New York, 1998.

11. K. S. Ang, Y. C. Leong and C. H. Lee, A new class of multisection $180^{\circ}$ hybrids based on cascadable hybrid-ring couplers, IEEE Trans Microwave Theory Tech 50 (2002), 2147-2152. 
TABLE 1

COMPARISON OF 1.8 GHZ RAT-RACE COUPLERS

\begin{tabular}{|c|c|c|c|c|}
\hline & $\begin{array}{c}\text { Area } \\
\left(\mathrm{mm}^{2}\right)\end{array}$ & $\begin{array}{l}\text { Polar curve } \\
\text { parameters }\end{array}$ & $\begin{array}{c}\text { Line widths } \\
\text { (mm) }\end{array}$ & $\begin{array}{c}\text { Bandwidth } \\
(\%)\end{array}$ \\
\hline $\begin{array}{l}\text { Conventional } \\
\text { circular rat- } \\
\text { race coupler }\end{array}$ & 1905.7 & $\begin{array}{l}r=a=24.19 \\
b=0\end{array}$ & $\begin{array}{l}w=1.75 \\
w_{l}=0.87\end{array}$ & $\begin{array}{l}\mathrm{I}-\mathrm{BW}^{*}=55 \\
\mathrm{M}-\mathrm{BW}^{\#}=23 \\
\mathrm{P}-\mathrm{BW}^{\Delta}=18\end{array}$ \\
\hline $\begin{array}{l}\text { Compact rat- } \\
\text { race coupler }\end{array}$ & 476.5 & $\begin{array}{l}a=7.95 \\
b=4.02 \\
n=12\end{array}$ & $\begin{array}{l}w=1.75 \\
w_{l}=0.69\end{array}$ & $\begin{array}{l}\mathrm{I}-\mathrm{BW}^{*}=56 \\
\mathrm{M}-\mathrm{BW}^{\#}=22 \\
\mathrm{P}-\mathrm{BW}^{\Delta}=17\end{array}$ \\
\hline
\end{tabular}

${ }^{\#} \mathrm{M}-\mathrm{BW}= \pm 0.5 \mathrm{~dB}$ magnitude tracking bandwidth, ports 2 and 3

${ }^{\Delta} \mathrm{P}-\mathrm{BW}= \pm 5^{\circ}$ phase tracking bandwidth, ports 2 and 3

TABLE 2

COMPARISON OF 1.8 GHZ BRANCH-LINE COUPLERS

\begin{tabular}{|c|c|c|c|c|}
\hline & $\begin{array}{c}\text { Area } \\
\left(\mathrm{mm}^{2}\right)\end{array}$ & $\begin{array}{l}\text { Polar curve } \\
\text { parameters }\end{array}$ & $\begin{array}{c}\text { Line widths } \\
(\mathrm{mm})\end{array}$ & $\begin{array}{c}\text { Bandwidth } \\
(\%)\end{array}$ \\
\hline $\begin{array}{l}\text { Conventional } \\
\text { circular } \\
\text { branch-line } \\
\text { coupler }\end{array}$ & 939.3 & $\begin{array}{l}r=a_{1}=15.83 \\
b_{1}=0 \\
r=a_{2}=15.83 \\
b_{2}=0\end{array}$ & $\begin{array}{l}w=1.75 \\
w_{1}=1.75 \\
w_{2}=2.92\end{array}$ & $\begin{array}{l}\mathrm{I}-\mathrm{BW}^{*}=31 \\
\mathrm{M}-\mathrm{BW}^{\#}=14 \\
\mathrm{P}-\mathrm{BW}^{\Delta}=19\end{array}$ \\
\hline $\begin{array}{l}\text { Compact } \\
\text { branch-line } \\
\text { coupler }\end{array}$ & 468.9 & $\begin{array}{l}a_{1}=8.47 \\
b_{1}=2.93 \\
n_{1}=12 \\
a_{2}=7.97 \\
b_{2}=3.43 \\
n_{2}=12\end{array}$ & $\begin{array}{l}w=1.75 \\
w_{1}=1.19 \\
w_{2}=1.64\end{array}$ & $\begin{array}{l}\mathrm{I}-\mathrm{BW}^{*}=32 \\
\mathrm{M}-\mathrm{BW}^{\#}=21 \\
\mathrm{P}-\mathrm{BW}^{\Delta}=24\end{array}$ \\
\hline
\end{tabular}

" $\mathrm{M}-\mathrm{BW}= \pm 0.5 \mathrm{~dB}$ magnitude tracking bandwidth, ports 2 and 3

${ }^{\Delta} \mathrm{P}-\mathrm{BW}= \pm 1^{\circ}$ phase tracking bandwidth, ports 2 and 3 


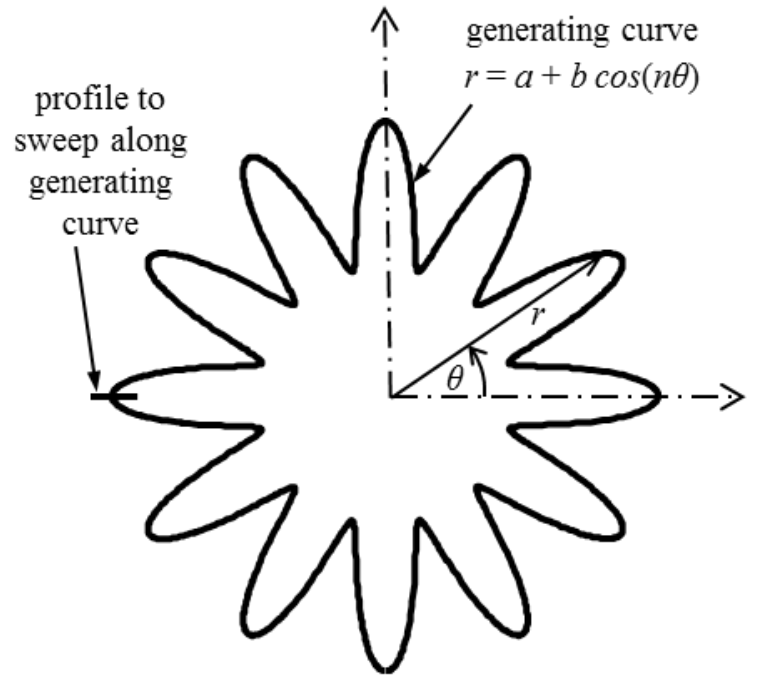

Figure 1 Polar generating curve and normal straight-line profile to sweep along the curve to generate a compact microstripline ring structure.

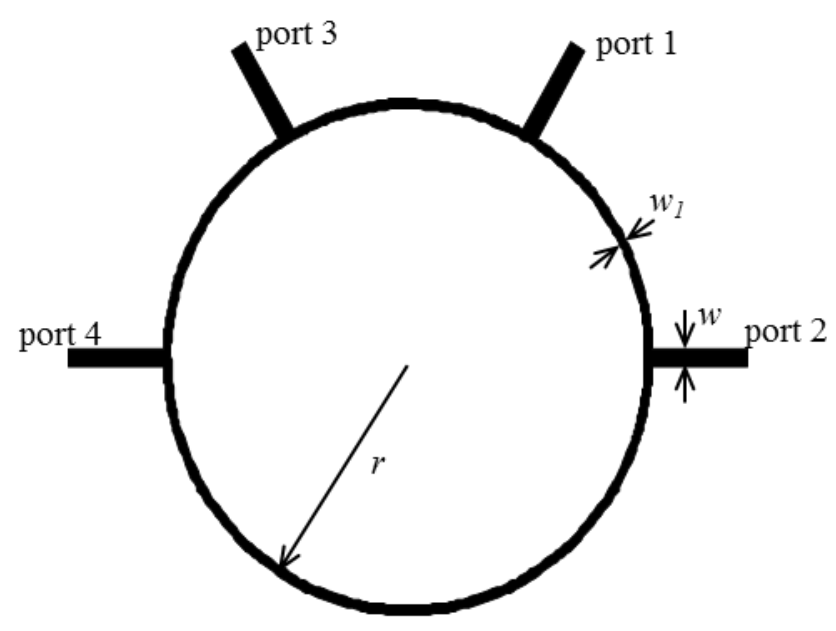

Figure 2 Conventional rat-race hybrid coupler.

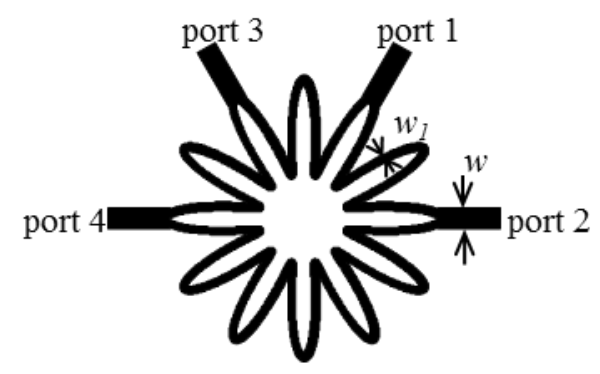

Figure 3 Quarter-size polar curve rat-race hybrid coupler. 


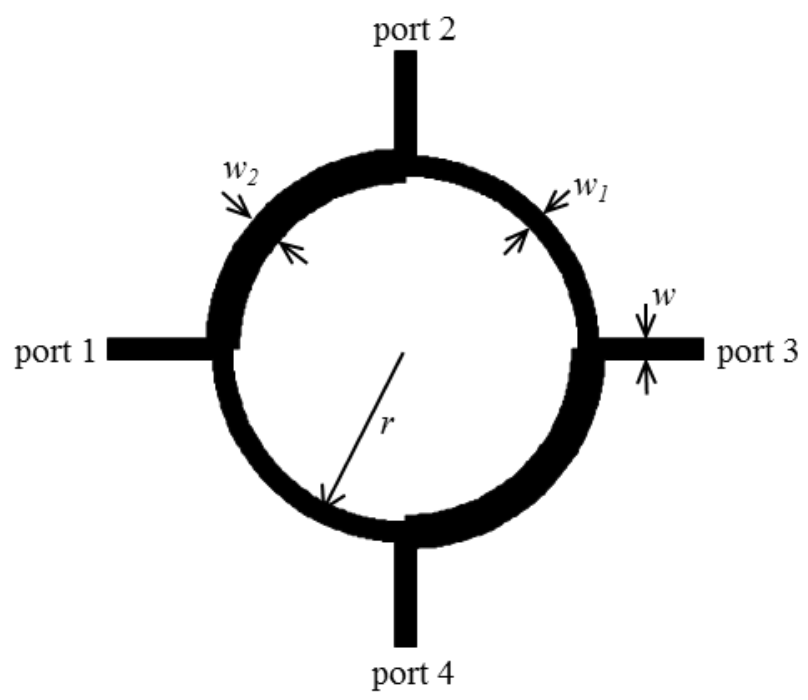

Figure 4 Conventional circular branch-line coupler.

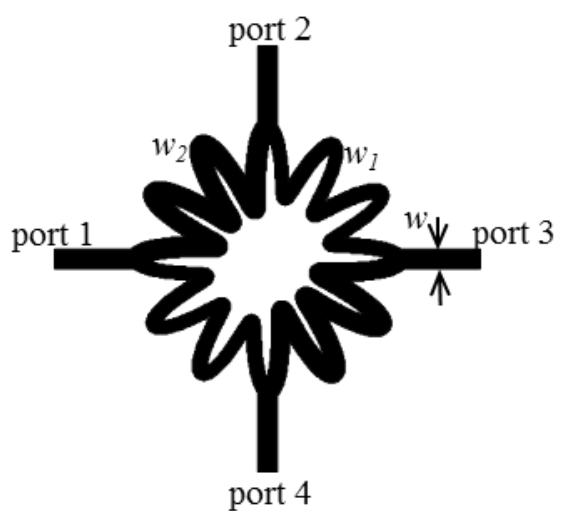

Figure 5 Half-size polar curve branch-line hybrid coupler.

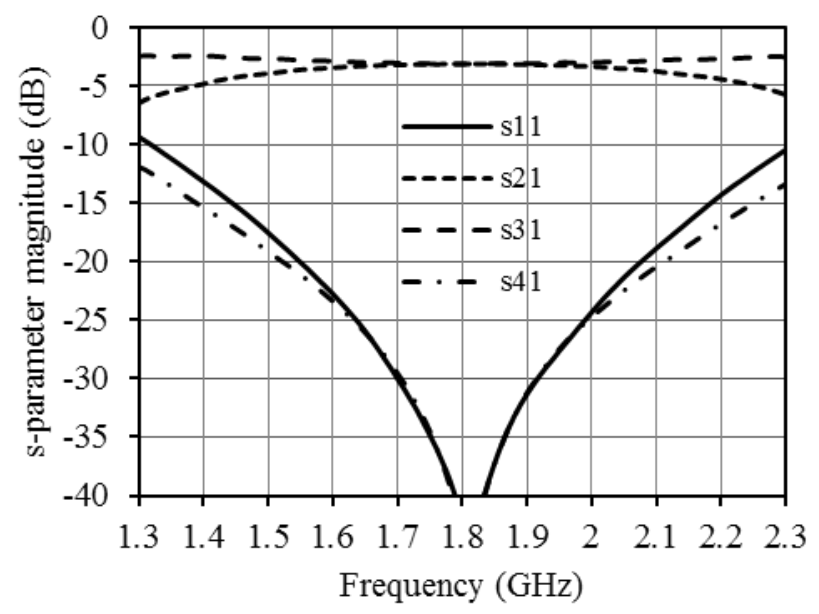

Figure 6 Measured s-parameter magnitudes of the conventional rat-race coupler. 


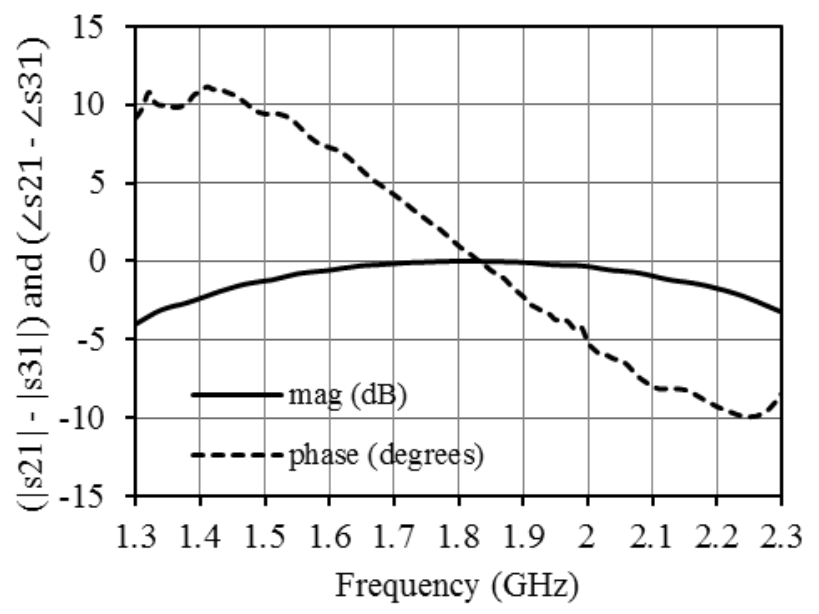

Figure 7 Measured difference in magnitude and phase between the two coupled ports of the conventional rat-race coupler.

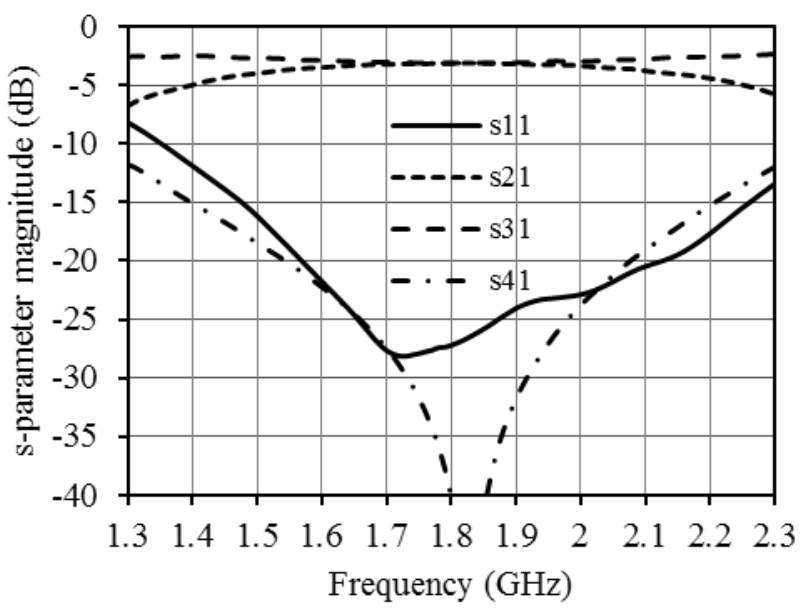

Figure 8 Measured s-parameter magnitudes of the quarter-size polar curve rat-race coupler.

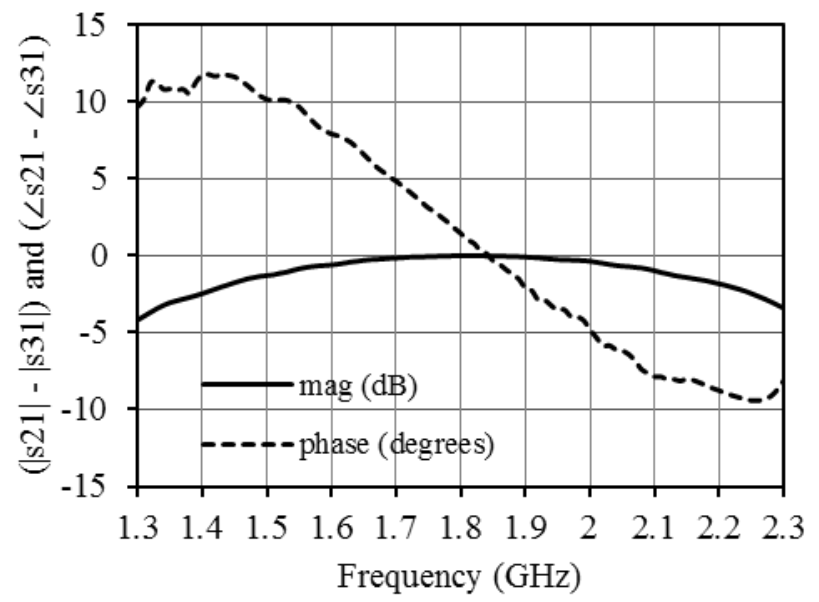

Figure 9 Measured difference in magnitude and phase between the two coupled ports of the quarter-size polar curve rat-race coupler. 


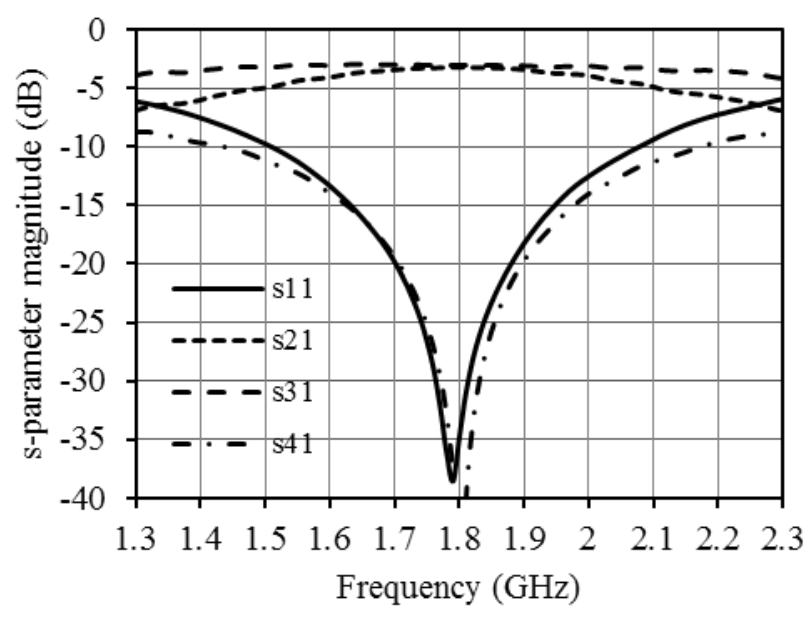

Figure 10 Measured s-parameter magnitudes of the conventional branch-line coupler.

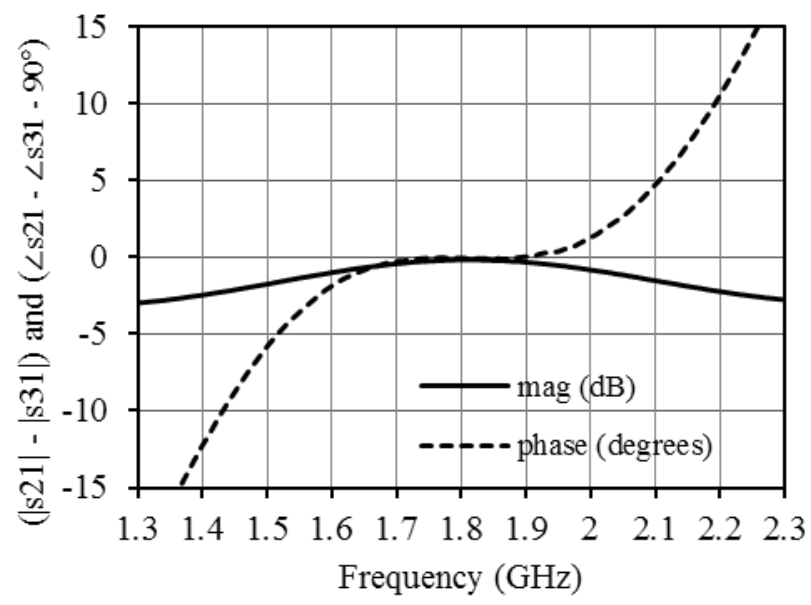

Figure 11 Measured difference in magnitude and phase between the two coupled ports of the conventional branch-line coupler.

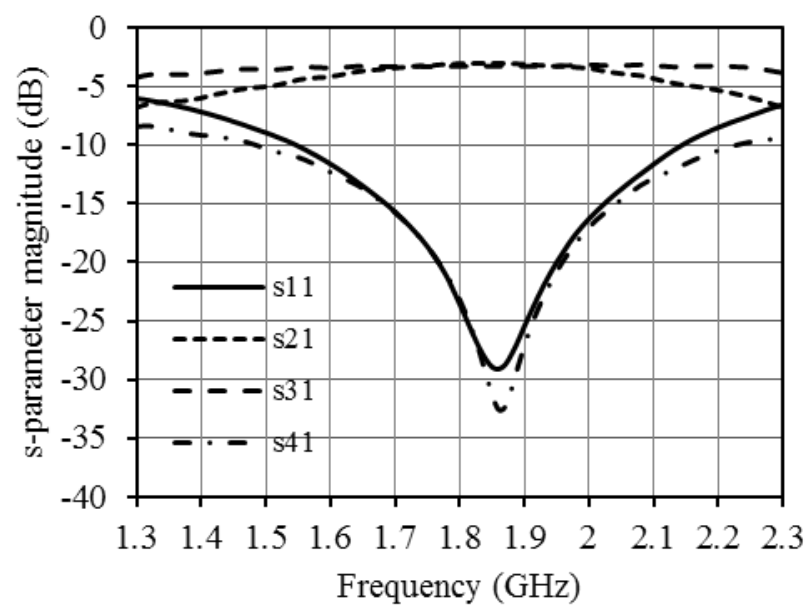

Figure 12 Measured s-parameter magnitudes of the half-size polar curve branch-line coupler. 


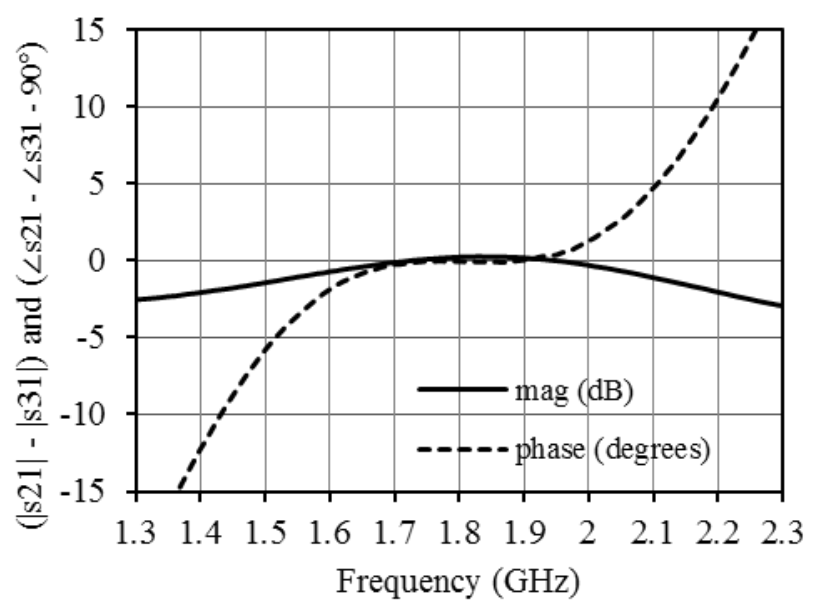

Figure 13 Measured difference in magnitude and phase between the two coupled ports of the half-size polar curve branch-line coupler. 